\title{
Telmo Roberto Strohaecker (1955-2016)
}

Luiz Carlos Pereira ${ }^{1}$ (1) Afonso Reguly ${ }^{2}$ (D)

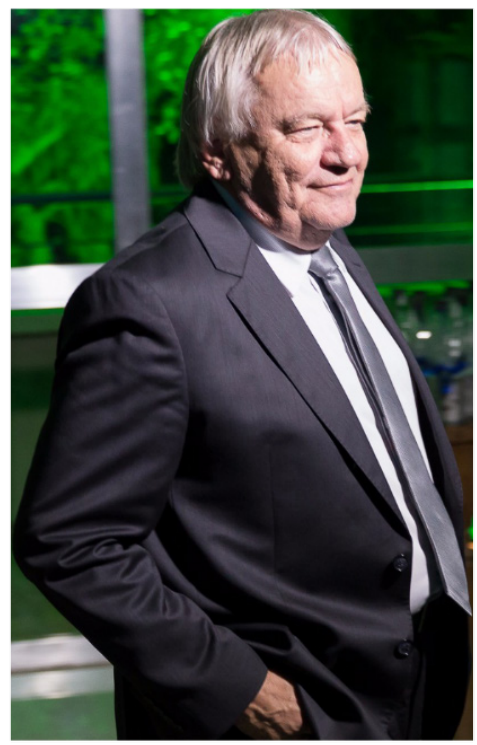

TMM dedicates this issue as a tribute to Prof Telmo Roberto Strohaecker, who made a significant contribution to Metallurgy and Materials Science in Brazil during his very productive career. We have invited Prof Afonso Reguly, his former student and one of our Executive Editors and Prof Luiz Carlos Pereira, his colleague and collaborator in many endeavors since their PhD studies at COPPE-UFRJ to write this issue's editorial.

André Luiz Vasconcellos da Costa e Silva - Chief Editor

This issue of TMM presents a series of articles in tribute to Prof. Telmo Roberto Strohaecker, who passed away prematurely in 2016. These articles mirror part of his career as scholar and researcher, being the result of national and international partnerships and the students trained throughout his career at UFRGS.

Prof. Telmo had his master (PPGE3M/UFRGS - 1980) and doctorate (COPPE/UFRJ - 1989) studies dedicated to the understanding of fracture in high-strength steels. He worked most of his career at PPGE3M/UFRGS where he acted as advisor for approximately 40 doctors and more than 90 master students in Metallurgical Engineering. He was very active in ABM, the Brazilian Society for Metallurgy, Materials and Mining. He was awarded the "Paulo Lobo Peçanha", "Luiz Dumont Villares" and "Acesita" awards for papers presented at ABM Conferences.

Besides his very expressive scientific production and the formation of Masters and Doctors at PPGE3M, he participated in the main scientific committees in the area of Engineering in the governmental institutions that promote research in Brazil (FINEP,CNPq and CAPES). He was also a great supporter of international exchanges of students and researchers, aiming at the development of teaching and research in partnerships with similar institutions in Germany, England, Spain, and Portugal.

An enthusiast of the academy-industry partnership for innovation, he was one of the driving forces behind the development of the Oil \& Gas industry in the South of Brazil, based on the technological research infrastructure installed under his coordination at the LAMEF/PPG3M/ UFRGS Laboratory. For his efforts in the technological development of Industry, he received the "Researcher of the Year" award from the Government of the State of Rio Grande do Sul, Brazil.

Prof Telmo's legacy continues through the EMBRAPII - LAMEF Unit, which currently has the participation of four UFRGS Professors. Through this initiative PhD, Masters and undergraduate students have to opportunity to work on projects that maintain and expand the technical-scientific partnerships between University and Industry as envisaged by Prof. Telmo Roberto Strohaecker.

Telmo's energy and enthusiasm during his career were an inspiration to a large number of Brazilian engineers and researchers.

Prof. Luiz Carlos Pereira, D.Sc., UFRJ

Prof. Afonso Reguly, D.Sc., UFRGS

${ }^{1}$ Universidade Federal do Rio de Janeiro, UFRJ, Rio de Janeiro, RJ, Brasil.

${ }^{2}$ Universidade Federal do Rio Grande do Sul, UFRGS, Porto Alegre, RS, Brasil. cited. 